\title{
Chromosome 7 translocation breakpoints in male carriers: clinical features and implications for genetic counseling
}

\author{
R.X. Wang, H.G. Zhang, Y. Pan, J.H. Zhu, F.G. Yue, L.T. Xue and R.Z. Liu \\ Center for Reproductive Medicine, Center for Prenatal Diagnosis, \\ First Hospital, Jilin University, Changchun, Jilin, China \\ Corresponding author: R.Z. Liu \\ E-mail:1rz410@126.com
}

Genet. Mol. Res. 15 (4): gmr15048948

Received July 6, 2016

Accepted August 15, 2016

Published October 17, 2016

DOI http://dx.doi.org/10.4238/gmr15048948

Copyright $(2016$ The Authors. This is an open-access article distributed under the terms of the Creative Commons Attribution ShareAlike (CC BY-SA) 4.0 License.

\begin{abstract}
Balanced reciprocal translocations are associated with reproductive failure. Some reciprocal translocation carriers exhibit azoospermia or oligozoospermia, and an association exists between these chromosomal abnormalities and recurrent abortion. Previous reports have indicated the involvement of chromosome 7 translocations in male infertility and recurrent miscarriage. A translocation breakpoint can occur within an important gene, interrupting its structure and leading to male infertility. However, clinical characteristics resulting from chromosome 7 translocation breakpoints have not been studied. Here, we report such breakpoints and their associated clinical features, to enable informed genetic counseling of carriers. Balanced reciprocal translocations were found in $1.57 \%$ of the tested patients. Among these 82 individuals, $14(17.07 \%)$ carried a chromosome 7 translocation, of which, five presented with pregestational infertility and clinical manifestations of oligozoospermia or necrospermia,
\end{abstract}


while nine presented with gestational infertility (i.e., were able to conceive, but often resulting in miscarriage). Breakpoints at $7 \mathrm{q} 31$ and $7 \mathrm{q} 36$ were associated with pregestational infertility, whereas those at $7 \mathrm{p} 10,7 \mathrm{q} 21.2,7 \mathrm{q} 22$, and $7 \mathrm{q} 32$ were connected to gestational infertility. However, the breakpoint at $7 \mathrm{p} 15$ was associated with both. Chromosome 7 translocation carriers with pregestational or gestational infertility should be counseled on chromosomal breakpoints and the various molecular technologies available for assisted reproduction.

Key words: Male infertility; Chromosome 7; Balanced translocation; Breakpoint; Genetic counseling

\section{INTRODUCTION}

Reciprocal translocation is closely related to infertility and recurrent miscarriage. Some reciprocal translocation carriers suffer oligozoospermia or severe oligozoospermia (Zhang et al., 2015c), and couples in which the male partner carries such a chromosomal abnormality are at increased risk of recurrent abortion (Gaboon et al., 2015; Tunç et al., 2016). Reproductive outcome and sperm parameters, including the presence of aneuploidy, in male carriers have received increasing attention over recent years (Li et al., 2015; Pastuszek et al., 2015; Zhang et al., 2015b). These effects are dependent on the specific chromosomes involved in the translocation, the locations of the breaks, and the frequency of chiasmata (Vozdova et al., 2008; Harton and Tempest, 2012; Godo et al., 2013). Previous reports have indicated the involvement of balanced reciprocal translocations of chromosome 7 in male infertility and recurrent miscarriage (Tharapel et al., 1985; Vozdova et al., 2013; Zhang et al., 2015c).

Most balanced chromosomal aberrations are not associated with a clinical phenotype; however, in some male patients, a translocation breakpoint is situated within an important gene, interrupting its structure and leading to infertility (Pernice et al., 2002; Bianco et al., 2011; Harton and Tempest, 2012). The dipeptidyl aminopeptidase-like protein 6 (DPP6) and contactin-associated protein-like $2(C A C N A 2 D 1)$ loci, mapped to chromosome 7 and incorporating breakpoints $7 \mathrm{q} 36.2$ and $7 \mathrm{q} 21.11$, are associated with azoospermia ( $\mathrm{Li}$ et al., 2014). Ichioka et al. (2005) identified breakpoints at 7q22 and 7q31 from a karyogram of a patient with non-obstructive azoospermia. In addition, most translocation breakpoints on chromosome 7 in men are associated with recurrent miscarriage (Kochhar and Ghosh, 2013; Zhang et al., 2015c; Tunç et al., 2016).

The aim of this study was to determine the correlation between clinical characteristics of male infertility and chromosome 7 translocation breakpoints. Furthermore, the importance of genetic counseling for infertile patients is highlighted.

\section{MATERIAL AND METHODS}

\section{Patients}

Five thousand two hundred and thirty-five men diagnosed with infertility or receiving counseling for infertility due to genetic causes were recruited from the outpatient clinic of the Centre for Reproductive Medicine at the First Hospital of Jilin University, Changchun,

Genetics and Molecular Research 15 (4): gmr15048948 
China, between July 2010 and December 2015. All patients underwent a thorough physical examination and semen analysis, and were required complete a detailed questionnaire pertaining to their smoking habits, marital status, medical history, and working conditions. Azoospermia and oligozoospermia were defined as previously described (Zhang et al., 2015b). The study protocol was approved by the Ethics Committee of the First Hospital of Jilin University, and written informed consent was obtained from all participants.

\section{Cytogenetic analysis}

All patients were also subjected to cytogenetic analysis. Peripheral blood $(0.5 \mathrm{~mL})$ was collected in sterile tubes containing $30 \mathrm{U} / \mathrm{mL}$ heparin. Lymphocytes were cultured in appropriate culture media (Yishengjun; Guangzhou Baidi Biotech, Guangzhou, China) for $72 \mathrm{~h}$, and subsequently treated with $20 \mathrm{mg} / \mathrm{mL}$ colcemid for $1 \mathrm{~h}$. G-banding of metaphase chromosomes and karyotype analysis were performed using previously published methods (Zhang et al., 2015a).

\section{RESULTS}

Conventional cytogenetic analysis identified a reciprocal translocation in 82 (1.57\%) participants, of which, $14(17.07 \%)$ carried a chromosome 7 translocation. Of these, five (5/14) exhibited pregestational infertility (with clinical manifestations of oligozoospermia, severe oligozoospermia, or necrospermia), and the remaining nine (9/14) suffered gestational infertility (the patients' partners were able to conceive, but tended to miscarry). Karyotyping of the 14 patients carrying chromosome 7 translocations is summarized in Table 1.

Table 1. Karyotypes of chromosome 7 translocation carriers and their clinical features.

\begin{tabular}{|c|c|c|}
\hline Infertility type & Clinical findings & Karyotype \\
\hline Pregestational & Oligozoospermia, severe oligozoospermia or necrospermia & $\begin{array}{l}\text { 46,XY,t(6;7)(q15;p15) } \\
46, X Y, t(7 ; 15)(\mathrm{p} 15 ; \mathrm{q} 15) \\
46, X Y, t(1 ; 7)(\mathrm{p} 34 ; \mathrm{q} 36) \\
46, X Y, t(7 ; 14)(\mathrm{q} 31 ; \mathrm{p} 12) \\
46, \mathrm{XY}, \mathrm{t}(7 ; 15)(\mathrm{q} 31 ; \mathrm{q} 22)\end{array}$ \\
\hline Gestational & Normal sperm density; history of miscarriage & $\begin{array}{l}46, \mathrm{XY}, \mathrm{t}(6 ; 7)(\mathrm{q} 13 ; \mathrm{p} 15) \\
46, \mathrm{XY}, \mathrm{t}(6 ; 7)(\mathrm{q} 25 ; \mathrm{p} 15) \\
46, \mathrm{XY}, \mathrm{t}(7 ; 9)(\mathrm{p} 10 ; \mathrm{q} 10) \\
46, \mathrm{XY}, \mathrm{t}(7 ; 10)(\mathrm{q} 22 ; \mathrm{p} 13) \\
46, \mathrm{XY}, \mathrm{t}(3 ; 7)(\mathrm{p} 23 ; \mathrm{q} 21.2) \\
46, \mathrm{XY}, \mathrm{t}(7 ; 8)(\mathrm{q} 32 ; \mathrm{p} 23) \\
46, \mathrm{XY}, \mathrm{t}(7 ; 10)(\mathrm{q} 32 ; \mathrm{q} 22) \\
46, \mathrm{XY}, \mathrm{t}(7 ; 10)(\mathrm{q} 32 ; \mathrm{q} 21) \\
46, \mathrm{XY}, \mathrm{t}(7 ; 8)(\mathrm{q} 32 ; \mathrm{q} 22)\end{array}$ \\
\hline
\end{tabular}

The most common breakpoints were at $7 \mathrm{p} 15$ and $7 \mathrm{q} 32$, being observed in four patients each. Those at $7 \mathrm{q} 31$ and $7 \mathrm{q} 36$ were associated with pregestational infertility, and those at $7 \mathrm{p} 10$, $7 \mathrm{q} 21.2,7 \mathrm{q} 22$, and $7 \mathrm{q} 32$ with gestational infertility. One breakpoint, $7 \mathrm{p} 15$, was connected to both infertility types (Table 2).

Genetics and Molecular Research 15 (4): gmr15048948 
Table 2. Incidence of breakpoints on chromosome 7.

\begin{tabular}{l|c|c|c}
\hline Breakpoint & Number of patients with pregestational infertility & Number of patients with gestational infertility & Total (\%) \\
\hline $\mathrm{p} 15$ & 2 & 2 & $4(28.57)$ \\
\hline $\mathrm{p} 10$ & & 1 & $1(7.14)$ \\
\hline $\mathrm{q} 21.2$ & & 1 & $1(7.14)$ \\
\hline $\mathrm{q} 2$ & 2 & 1 & $1(7.14)$ \\
\hline $\mathrm{q} 31$ & & & $2(14.29)$ \\
\hline $\mathrm{q} 32$ & 1 & 4 & $4(28.57)$ \\
\hline $\mathrm{q} 36$ & & & $1(7.14)$ \\
\hline
\end{tabular}

\section{DISCUSSION}

Karyotype analysis remains the most powerful and affordable of all molecular diagnostic techniques; therefore, this method continues to be widely applied in this field (Pasquier et al., 2016). Carriers of reciprocal translocations, while phenotypically normal, may experience reduced fertility and spontaneous abortions (Harton and Tempest, 2012). Previous studies have reported the involvement of balanced reciprocal translocations on chromosome 7 in male infertility and recurrent miscarriage (Tharapel et al., 1985; Vozdova et al., 2013; Zhang et al., 2015c). In the current investigation, reciprocal translocation was identified in 82 $(1.57 \%)$ infertile men, 14 of whom (17.07\%) carried chromosome 7 translocations. The major limitation of this study was the small number of such carriers; moreover, the molecular effect of these translocations was not investigated here, necessitating further research.

Balanced chromosomal translocations are associated with increased risk of pregnancy loss, fetal death, and male infertility (Godo et al., 2013). The latter is divided into two types of reproductive failure: pregestational and gestational infertility, both of which were found to be associated with chromosome 7 breakpoints in this study. Breakpoints at $7 \mathrm{q} 31$ and $7 \mathrm{q} 36$ were found in patients with pregestational infertility, whereas those at $7 \mathrm{p} 10,7 \mathrm{q} 21.2,7 \mathrm{q} 22$, and $7 \mathrm{q} 32$ were identified in men suffering gestational infertility. However, a breakpoint at $7 \mathrm{p} 15$ was associated with both infertility types. A breakpoint at $7 \mathrm{q} 31$ was identified in two pregestational infertility patients. The sperm adhesion molecule 1 (SPAM1) gene maps to the long arm of chromosome 7, at this same position (Jones et al., 1995), and epididymal SPAM1 is a marker of sperm maturation (Martin-DeLeon, 2006). In addition, RNF32, located on chromosome $7 \mathrm{q} 36$, is expressed during spermatogenesis, suggesting a possible role in sperm formation (van Baren et al., 2002). These observations indicate that breakpoints at $7 \mathrm{q} 31$ and $7 q 36$ may affect spermatogenesis by altering the functionality of these genes. The breakpoint at $7 \mathrm{q} 15$ was identified in two pregestational and two gestational infertility patients. In the former, breakpoints at $6 \mathrm{q} 15$ and $15 \mathrm{q} 15$ were also noted. SAMP32, encoding a testis-specific, isoantigenic sperm acrosomal membrane-associated protein, maps to chromosome $6 \mathrm{q} 15$ (Hao et al., 2002), and CATSPER2, a gene associated with nonsyndromic male infertility, is located on $15 \mathrm{q} 15$ (Avidan et al., 2003). This suggests that the breakpoint at $7 \mathrm{p} 15$ may not in fact affect spermatogenesis. Consistent with our findings, Vozdova et al. (2013) reported a correlation between a 7q36 breakpoint and impaired spermatogenesis. And the associations between those at 7q21.2, 7q22, and 7q32 and recurrent abortion are also reported (Niroumanesh et al., 2011; Kochhar and Ghosh, 2013, Zhang et al., 2015c). A survey of related, recently published articles revealed a close link between chromosome 7 translocation breakpoint carriers and male infertility and reproductive failure. Chromosome 7 karyotypes and breakpoints and their related clinical effects are summarized in Table 3. In general, breakpoints at 7q31 and 7q36

Genetics and Molecular Research 15 (4): gmr15048948 
tend to be associated with pregestational infertility, while those at $7 \mathrm{q} 21.2,7 \mathrm{q} 22$, and $7 \mathrm{q} 32$ demonstrate a relationship with gestational infertility.

Table 3. Chromosome 7 translocation breakpoints and associated clinical features reported in previous publications.

\begin{tabular}{|c|c|c|c|}
\hline Karyotype & Breakpoints & Clinical findings & Reference \\
\hline $\mathrm{t}(1 ; 7)$ & $1 \mathrm{p} 32 ; 7 \mathrm{q} 22$ & Oligoasthenospermia & Vozdova et al., 2013 \\
\hline $\mathrm{t}(2 ; 7)$ & $2 \mathrm{p} 23 ; 7 \mathrm{p} 22$ & Recurrent fetal wastage & Fryns and Van Buggenhout, 1998 \\
\hline $\mathrm{t}(2 ; 7)$ & $2 \mathrm{p} 13 ; 7 \mathrm{q} 34$ & Normospermia & Vozdova et al., 2013 \\
\hline $\mathrm{t}(2 ; 7)$ & $2 \mathrm{p} 13 ; 7 \mathrm{q} 32$ & Oligoasthenospermia & Vozdova et al., 2013 \\
\hline $\mathrm{t}(2 ; 7)$ & $2 \mathrm{q} 31 ; 7 \mathrm{q} 34$ & Asthenospermia & Vozdova et al., 2013 \\
\hline $\mathrm{t}(3 ; 7)$ & $3 \mathrm{p} 23 ; 7 \mathrm{q} 21.2$ & Recurrent spontaneous abortion & Zhang et al., 2015c \\
\hline $\mathrm{t}(4 ; 7)$ & $4 \mathrm{q} 31 ; 7 \mathrm{p} 22$ & Recurrent pregnancy loss & Kochhar and Ghosh, 2013 \\
\hline $\mathrm{t}(4 ; 7)$ & $4 \mathrm{q} 2.7 ; 7 \mathrm{p} 14$ & Normospermia & Vozdova et al., 2013 \\
\hline $\mathrm{t}(4 ; 7)$ & $4 \mathrm{q} 2.7 ; 7 \mathrm{p} 14$ & Normospermia & Vozdova et al., 2013 \\
\hline $\mathrm{t}(5 ; 7)$ & $5 \mathrm{p} 13 ; 7 \mathrm{p} 15$ & Recurrent pregnancy loss & Kochhar and Ghosh, 2013 \\
\hline $\mathrm{t}(5 ; 7)$ & $5 \mathrm{p} 15 ; 7 \mathrm{p} 14$ & Recurrent spontaneous pregnancy loss & Gada Saxena et al., 2012 \\
\hline $\mathrm{t}(6 ; 7)$ & $6 \mathrm{p} 22 ; 7 \mathrm{q} 34$ & Recurrent fetal wastage & Fryns and Van Buggenhout, 1998 \\
\hline $\mathrm{t}(6 ; 7)$ & $6 \mathrm{q} 15 ; 7 \mathrm{p} 15$ & Recurrent spontaneous abortion & Zhang et al., $2015 \mathrm{c}$ \\
\hline $\mathrm{t}(6 ; 7)$ & $6 \mathrm{q} 25 ; 7 \mathrm{q} 34$ & Normospermia & Vozdova et al., 2013 \\
\hline $\mathrm{t}(7 ; 8)$ & $7 \mathrm{q} 32 ; 8 \mathrm{q} 22$ & Recurrent spontaneous abortion & Zhang et al., 2015c \\
\hline $\mathrm{t}(7 ; 9)$ & $7 \mathrm{p} 15.2 ; 9 \mathrm{q} 34.1$ & Normospermia & Vozdova et al., 2013 \\
\hline $\mathrm{t}(7 ; 10)$ & $7 \mathrm{p} 15.1 ; 10 \mathrm{q} 23.2$ & Normospermia & Vozdova et al., 2013 \\
\hline $\mathrm{t}(7 ; 10)$ & $7 \mathrm{q} 34 ; 10 \mathrm{q} 24$ & Normospermia & Vozdova et al., 2013 \\
\hline $\mathrm{t}(7 ; 10)$ & $7 \mathrm{q} 36 ; 10 \mathrm{q} 24.3$ & Teratospermia & Vozdova et al., 2013 \\
\hline $\mathrm{t}(7 ; 10)$ & $7 \mathrm{q} 32 ; 10 \mathrm{q} 21$ & Recurrent spontaneous abortion & Zhang et al., 2015c \\
\hline$t(7 ; 12)$ & $7 \mathrm{p} 13 ; 12 \mathrm{q} 15$ & Normospermia & Vozdova et al., 2013 \\
\hline $\mathrm{t}(7 ; 13)$ & 7q11.22;13q21.3 & Teratospermia & Vozdova et al., 2013 \\
\hline $\mathrm{t}(7 ; 13)$ & $7 q 22 ; 13 q 24$ & Abortions & Niroumanesh et al., 2011 \\
\hline $\mathrm{t}(7 ; 13)$ & $7 \mathrm{p} 15 ; 13 \mathrm{q} 33$ & Recurrent fetal wastage & Fryns and Van Buggenhout, 1998 \\
\hline $\mathrm{t}(7 ; 13)$ & $7 q 31 ; 13 q 31$ & Recurrent fetal wastage & Fryns and Van Buggenhout, 1998 \\
\hline $\mathrm{t}(7 ; 13)$ & $7 q 35 ; 13 q 13$ & Infertility & Gada Saxena et al., 2012 \\
\hline $\mathrm{t}(7 ; 13)$ & $7 \mathrm{p} 13 ; 13 \mathrm{q} 21.2$ & Recurrent pregnancy loss & Kochhar and Ghosh, 2013 \\
\hline $\mathrm{t}(7 ; 14)$ & 7pter;14q22 & Recurrent spontaneous abortion & Tunç et al., 2016 \\
\hline $\mathrm{t}(7 ; 14)$ & $7 q 36 ; 14 q 11$ & Recurrent spontaneous abortion & Tunç et al., 2016 \\
\hline$t(7 ; 14)$ & $7 \mathrm{q} 33 ; 14 \mathrm{q} 32.3$ & Recurrent miscarriage & Dutta et al., 2011 \\
\hline $\mathrm{t}(7 ; 15)$ & $7 \mathrm{p} 15 ; 15 \mathrm{q} 15$ & Oligozoospermia & Zhang et al., 2015c \\
\hline $\mathrm{t}(7 ; 16)$ & $7 \mathrm{q} 32 ; 16 \mathrm{q} 24$ & Recurrent pregnancy loss & Kochhar and Ghosh, 2013 \\
\hline $\mathrm{t}(7 ; 17)$ & $7 \mathrm{q} 32 ; 17 \mathrm{q} 21.2$ & Infertility & Gada Saxena et al.,2012 \\
\hline $\mathrm{t}(7 ; 18)$ & $7 \mathrm{p} 21.3 ; 18 \mathrm{q} 12.2$ & Repeated spontaneous abortion & Ghazaey et al., 2015 \\
\hline
\end{tabular}

Carriers of balanced translocations must receive appropriate counseling to inform them of suitable fertility treatment options (Zhang et al., 2015b). Patients with pregestational infertility related to oligozoospermia must be counseled regarding chromosomal breakpoints and in vitro fertilization/intracytoplasmic sperm injection. Likewise, those with gestational infertility should be given guidance concerning prenatal testing or preimplantation genetic diagnosis, as these patients are at increased risk of implantation failure and miscarriage (Vozdova et al., 2013).

In conclusion, balanced reciprocal translocations were observed in $1.57 \%$ of the infertile male patients tested. Of these, 14 (17.07\%) carried chromosome 7 translocations, five presenting with pregestational and nine with gestational infertility. Breakpoints at $7 \mathrm{q} 31$ and $7 \mathrm{q} 36$ were associated with pregestational infertility, while those at $7 \mathrm{q} 21.2,7 \mathrm{q} 22$, and $7 \mathrm{q} 32$ correlated with gestational infertility. Carriers of chromosome 7 translocations suffering infertility of either type should be counseled on chromosomal breakpoints and the various molecular technologies available to assist reproduction. 


\section{Conflicts of interest}

The authors declare no conflict of interest.

\section{ACKNOWLEDGMENTS}

We express our sincere gratitude to the staff of the Genetics Laboratory, Center for Prenatal Diagnosis, First Hospital, Jilin University, for their support. Research supported by the National Natural Science Fund (\#81471515).

\section{REFERENCES}

Avidan N, Tamary H, Dgany O, Cattan D, et al. (2003). CATSPER2, a human autosomal nonsyndromic male infertility gene. Eur. J. Hum. Genet. 11: 497-502. http://dx.doi.org/10.1038/sj.ejhg.5200991

Bianco B, Christofolini D, Gava M, Mafra F, et al. (2011). Severe oligospermia associated with a unique balanced reciprocal translocation t(6;12)(q23;q24.3): male infertility related to t(6;12). Andrologia 43: 145-148. http://dx.doi. org/10.1111/j.1439-0272.2009.01020.x

Dutta UR, Rajitha P, Pidugu VK and Dalal AB (2011). Cytogenetic abnormalities in 1162 couples with recurrent miscarriages in southern region of India: report and review. J. Assist. Reprod. Genet. 28: 145-149. http://dx.doi. org $/ 10.1007 / \mathrm{s} 10815-010-9492-6$

Fryns JP and Van Buggenhout G (1998). Structural chromosome rearrangements in couples with recurrent fetal wastage. Eur. J. Obstet. Gynecol. Reprod. Biol. 81: 171-176. http://dx.doi.org/10.1016/S0301-2115(98)00185-7

Gaboon NE, Mohamed AR, Elsayed SM, Zaki OK, et al. (2015). Structural chromosomal abnormalities in couples with recurrent abortion in Egypt. Turk. J. Med. Sci. 45: 208-213. http://dx.doi.org/10.3906/sag-1310-5

Gada Saxena S, Desai K, Shewale L, Ranjan P, et al. (2012). Chromosomal aberrations in 2000 couples of Indian ethnicity with reproductive failure. Reprod. Biomed. Online 25: 209-218. http://dx.doi.org/10.1016/j.rbmo.2012.04.004

Ghazaey S, Keify F, Mirzaei F, Maleki M, et al. (2015). Chromosomal analysis of couples with repeated spontaneous abortions in northeastern iran. Int. J. Fertil. Steril. 9: 47-54.

Godo A, Blanco J, Vidal F and Anton E (2013). Accumulation of numerical and structural chromosome imbalances in spermatozoa from reciprocal translocation carriers. Hum. Reprod. 28: 840-849. http://dx.doi.org/10.1093/humrep/des431

Hao Z, Wolkowicz MJ, Shetty J, Klotz K, et al. (2002). SAMP32, a testis-specific, isoantigenic sperm acrosomal membrane-associated protein. Biol. Reprod. 66: 735-744. http://dx.doi.org/10.1095/biolreprod66.3.735

Harton GL and Tempest HG (2012). Chromosomal disorders and male infertility. Asian J. Androl. 14: 32-39. http://dx.doi. org/10.1038/aja.2011.66

Ichioka K, Yoshimura K, Honda T, Takahashi A, et al. (2005). Paracentric inversion of chromosome 7(q22-31) associated with nonobstructive azoospermia. Fertil. Steril. 83: 455-456. http://dx.doi.org/10.1016/j.fertnstert.2004.06.070

Jones MH, Davey PM, Aplin H and Affara NA (1995). Expression analysis, genomic structure, and mapping to 7q31 of the human sperm adhesion molecule gene SPAM1. Genomics 29: 796-800. http://dx.doi.org/10.1006/geno.1995.9931

Kochhar PK and Ghosh P (2013). Reproductive outcome of couples with recurrent miscarriage and balanced chromosomal abnormalities. J. Obstet. Gynaecol. Res. 39: 113-120. http://dx.doi.org/10.1111/j.1447-0756.2012.01905.x

Li L, Chen H, Yin C, Yang C, et al. (2014). Mapping breakpoints of a familial chromosome insertion (18,7) (q22.1; q36.2q21.11) to DPP6 and CACNA2D1 genes in an azoospermic male. Gene 547: 43-49. http://dx.doi.org/10.1016/j. gene.2014.06.007

Li LL, Dong Y, Wang RX, An N, et al. (2015). Sperm aneuploidy and implications for genetic counseling in a pedigree of three t 1 ; 3) balanced translocation carriers. Genet. Mol. Res. 14: 5003-5009. http://dx.doi.org/10.4238/2015.May.12.3

Martin-DeLeon PA (2006). Epididymal SPAM1 and its impact on sperm function. Mol. Cell. Endocrinol. 250: 114-121. http://dx.doi.org/10.1016/j.mce.2005.12.033

Niroumanesh S, Mehdipour P, Farajpour A and Darvish S (2011). A cytogenetic study of couples with repeated spontaneous abortions. Ann. Saudi Med. 31: 77-79. http://dx.doi.org/10.4103/0256-4947.75785

Pasquier L, Fradin M, Chérot E, Martin-Coignard D, et al. (2016). Karyotype is not dead (yet)! Eur. J. Med. Genet. 59: 11-15. http://dx.doi.org/10.1016/j.ejmg.2015.11.016

Pastuszek E, Kiewisz J, Kulwikowska PM, Lukaszuk M, et al. (2015). Sperm parameters and DNA fragmentation of balanced chromosomal rearrangements carriers. Folia Histochem. Cytobiol. 53: 314-321. http://dx.doi.org/10.5603/ fhc.a2015.0032

Genetics and Molecular Research 15 (4): gmr15048948 
Pernice F, Mazza G, Puglisi D, Luppino MG, et al. (2002). Nonrobertsonian translocation $\mathrm{t}(6 ; 11)$ is associated with infertility in an oligoazoospermic male. Fertil. Steril. 78: 192-194. http://dx.doi.org/10.1016/S0015-0282(02)03180-1

Tharapel AT, Tharapel SA and Bannerman RM (1985). Recurrent pregnancy losses and parental chromosome abnormalities: a review. Br. J. Obstet. Gynaecol. 92: 899-914. http://dx.doi.org/10.1111/j.1471-0528.1985.tb03069.x

Tunç E, Tanriverdi N, Demirhan O, Süleymanova D, et al. (2016). Chromosomal analyses of 1510 couples who have experienced recurrent spontaneous abortions. Reprod. Biomed. Online 32: 414-419. http://dx.doi.org/10.1016/j. rbmo.2016.01.006

van Baren MJ, van der Linde HC, Breedveld GJ, Baarends WM, et al. (2002). A double RING-H2 domain in RNF32, a gene expressed during sperm formation. Biochem. Biophys. Res. Commun. 292: 58-65. http://dx.doi.org/10.1006/ bbrc. 2002.6612

Vozdova M, Oracova E, Horinova V and Rubes J (2008). Sperm fluorescence in situ hybridization study of meiotic segregation and an interchromosomal effect in carriers of t(11;18). Hum. Reprod. 23: 581-588. http://dx.doi. org/10.1093/humrep/dem345

Vozdova M, Oracova E, Kasikova K, Prinosilova P, et al. (2013). Balanced chromosomal translocations in men: relationships among semen parameters, chromatin integrity, sperm meiotic segregation and aneuploidy. J. Assist. Reprod. Genet. 30: 391-405. http://dx.doi.org/10.1007/s10815-012-9921-9

Zhang HG, Liu XY, Hou Y, Chen S, et al. (2015a). Reproductive outcome of a case with familial balanced translocation t(3;6): implications for genetic counseling. Genet. Mol. Res. 14: 2809-2815. http://dx.doi.org/10.4238/2015. March.31.11

Zhang HG, Wang RX, Li LL, Sun WT, et al. (2015b). Male carriers of balanced reciprocal translocations in Northeast China: sperm count, reproductive performance, and genetic counseling. Genet. Mol. Res. 14: 18792-18798. http:// dx.doi.org/10.4238/2015.December.28.28

Zhang M, Fan HT, Zhang QS, Wang XY, et al. (2015c). Genetic screening and evaluation for chromosomal abnormalities of infertile males in Jilin Province, China. Genet. Mol. Res. 14: 16178-16184. http://dx.doi.org/10.4238/2015. December.8.7 